\title{
Tradición frente a Recepción clásica: Historia frente a Estética, autor frente a lector ${ }^{1}$
}

Tradition versus Classical Reception:

History versus Aesthetics, Author versus Reader

\author{
Francisco GARCÍA JURADO \\ Universidad Complutense de Madrid \\ pacogj@ucm.es
}

\begin{abstract}
RESUMEN: Este trabajo pretende llevar a cabo una reflexión acerca de la nueva realidad que se viene dando en el marco de la actual disciplina de la Tradición clásica: la irrupción de los estudios sobre Recepción, más conocidos como "Reception Studies", para abordar la relectura de los clásicos grecolatinos a lo largo del tiempo.
\end{abstract}

ABSTRACT: This paper aims to conduct a reflection on the new reality that has occurred in the context of the present discipline of the Classical Tradition: the emergence of Reception Studies, in order to rereading Greek and Latin Classics over time.

Palabras Clave: Tradición clásica, Recepción, Teoría literaria, Historia, Método.

KEY wORDS: Classical Tradition, Reception, Literary Theory, History, Method.

RECIBIDO: 16 de enero de 2015 - ACEPTADO: 3 de junio de 2015.

\section{Introducción: el contexto de este estudio}

Desde el año 2013 venimos desarrollando una línea de investigación titulada "Tradición clásica: teorías y estéticas de la modernidad". ${ }^{2}$ Con ella nos hemos propuesto llevar a cabo una revisión global acerca de los aspectos conceptuales, históricos y metodológicos concernientes a la Tradición clásica como disciplina académica que estudia las relaciones entre el mundo antiguo y el moderno. Esta línea de investigación comenzó a cobrar vida en marzo de 2013, cuando, por encargo de la Sección

1 Ponencia de clausura presentada en el IV Congreso Internacional de Estudios Clásicos. Universidad Nacional Aútónoma de México 20-24 de octubre de 2014. Este trabajo se integra en la línea de investigación "Tradición clásica: teorías y estéticas de la modernidad" dentro del proyecto FFI2013-41976 (2015-2017), financiado por el Ministerio de Economía y Competitividad.

${ }^{2}$ El Dr. Javier Espino, desde la Universidad Nacional Autónoma de México, y el autor de este artículo, desde la Universidad Complutense de Madrid, somos los responsables de esta línea de investigación. 
aragonesa de la Sociedad Española de Estudios Clásicos, presentamos en la Universidad de Zaragoza una ponencia que llevaba el título de "Las metamorfosis de la Tradición clásica". En este trabajo logramos esbozar tres aspectos clave:

- La cuestión conceptual: delimitación de las etiquetas que definen tales estudios.

- La cuestión historiográfica: periodización de la disciplina.

- La cuestión metodológica: reflexión sobre los diferentes paradigmas o modelos de estudio.

En cualquier caso, el estudio de la Tradición clásica es en este momento un asunto global y, como luego trataremos de justificar, supone un viaje por diversas tradiciones clásicas, así como por una imprevista variedad de recepciones. Desde tales presupuestos, es necesario poner de manifiesto la necesidad de llevar a cabo una reflexión sobre la disciplina, de igual manera que ocurre (o debería ocurrir) dentro de cualquier otra disciplina académica. En este sentido, y sobre presupuestos de la Sociología de Pierre Bourdieu, Jorge Bergua hace las siguientes reflexiones:

[...] creo que es importante en todas las ciencias -y quiero pensar que en el estudio de la literatura también puede serlo- la reflexión epistemológica, especialmente con conceptos clave que, de tanto usarse, pasan desapercibidos y con ellos todos los valores o creencias de los que son portadores. ${ }^{3}$

Así las cosas, queremos llevar a cabo esta reflexión desde los tres puntos de vista ya señalados, a saber, (a) la cuestión conceptual, en especial para dilucidar cuándo y por qué se configuran las etiquetas de "Tradición" y "Recepción" clásica, (b) la historia de las disciplinas, en aras a establecer una periodización que nos sitúe en el tiempo de la Historia general, y (c) los métodos que configuran sus estudios, dado que es en este ámbito donde encontraremos algunas de las diferencias más notables. Este triple esquema es, por tanto, el que va a configurar el propio desarrollo del presente trabajo. En definitiva, nuestro propósito es apreciar cómo se ha ido transformando el propio concepto de Tradición clásica a partir del auge de los estudios de Recepción. Todo ello no deja de ser más que

${ }^{3}$ Bergua 2003, p. 11. 
el fruto de un mundo en constante crisis y una prueba de que nuestros estudios no dejan de ser la relectura presente de un pasado en incesante reinvención. Como oportunamente señaló Benedetto Croce, toda Historia, por antigua que ésta sea, se convierte en Historia contemporánea. ${ }^{4}$

\section{Entre Tradición clásica y Recepción. Cuestiones de concepto}

Pocos lugares son tan aptos para comprender cómo nació la etiqueta de "Tradición clásica" como el "Parco Virgiliano", en Posillipo. Es un lugar mítico, sobre todo para quienes creemos todavía que hay que leer viajando y viajar leyendo. Como bien recuerda César Antonio Molina, el nombre de Posillipo (Pausilipo) significa "el lugar que calma el dolor". 5 Desde hace siglos se ha creído que allí, precisamente en un mausoleo encaramado sobre una imponente roca desde la que se divisa la bahía de Nápoles, está enterrado Virgilio. No en vano, unas centurias más tarde se erigió al pie de esa misma roca la tumba del poeta Giacomo Leopardi. Virgilio se convirtió, gracias a este lugar legendario, en objeto de peregrinación para los viajeros a Italia y, asimismo, en parte de una leyenda popular que lo transformó nada menos que en mago. No en vano, Virgilio había hablado del advenimiento de una nueva era, y ya sabemos que la figura del adivino no está lejos de la del hacedor de portentos. Justamente, estas leyendas populares fueron las que hicieron que el filólogo Domenico Comparetti, en su imprescindible estudio sobre Virgilio en la Edad Media, publicado en 1872, distinguiera entre un "Virgilio culto", el poeta, y un "Virgilio popular", el mago. ${ }^{6}$ Tradición culta y popular confluían, por tanto, en un poeta antiguo y pagano que había seguido siendo admirado durante toda la Edad Media. Como bien observó Gabriel Laguna (2004), fue Comparetti quien por primera vez combinó los adjetivos "antigua" y "clásica" para hablar de la "tradición" grecolatina,

4 "Los requerimientos prácticos que laten bajo cada juicio histórico dan a toda la historia carácter de «historia contemporánea», por lejanos en el tiempo que puedan parecer los hechos por ella referidos; la historia, en realidad, está en relación con las necesidades actuales y la situación presente en que vibran aquellos hechos" (Croce 2005, p. 19).

${ }^{5}$ Molina 2009, p. 9.

${ }^{6}$ Véase Comparetti 1872, especialmente en la segunda parte de su obra: "Virgilio nella leggenda popolare", opuesta a la que el mismo Comparetti denomina "tradizione letteraria fino a Dante". 
probablemente en un intento de delimitar su ámbito culto frente al de las propias tradiciones populares. Sobre esta observación, en dos trabajos anteriores hemos tratado acerca del peculiar e interesante proceso por el cual se creó y fue configurando la etiqueta de "Tradición clásica". ${ }^{7}$ Lo más significativo de tal etiqueta es que no nació a partir de la mera adición de un adjetivo ("clásica") a un sustantivo ("tradición”), sino que tal juntura supuso toda una restricción de sentido para la que hasta entonces había sido la "tradición" por antonomasia, es decir, la grecolatina. A lo largo del siglo XIX observamos, gracias a los presupuestos románticos, el auge de otras tradiciones, en particular las populares y las modernas. Este nuevo estado de cosas fue el que dio lugar al nacimiento de la disciplina que hemos terminado conociendo como "Tradición clásica" a lo largo del siglo XX.

De esta forma, la etiqueta "Tradición clásica" tiene una fecha de creación que quizá sorprenda a algunas personas por su relativo carácter reciente. Sin embargo, a la hora de comparar las etiquetas de "Tradición” y "Recepción clásica", la primera característica que apreciamos es la de la desproporción temporal que hay entre ambas acuñaciones. Mientras que la primera data de finales del siglo XIX (gracias al ya citado Comparetti, 1872) y su acuñación definitiva y universal no tiene lugar hasta mediados del siglo XX (por obra de Gilbert Highet, 1949), la segunda nace a finales de los años 60 del siglo Xx (precisamente la Rezeptionästhetik de Hans Robert Jauss, 2000) y no se constituye como tal etiqueta (Classical Receptions) hasta el siglo XXI. Por su parte, al tener el término "Recepción" un carácter general, ${ }^{8}$ el adjetivo "clásico" contribuyó asimismo a cerrar una nueva disciplina ligada, en principio, al ámbito de los Estudios clásicos, aunque no de manera excluyente. Concretando lo dicho hasta ahora, la etiqueta "Tradición clásica" no se universalizó hasta que Highet la puso como título de su conocida monografía, publicada en 1949. La llamada "Estética de la Recepción", por su parte, no aparece hasta el año de 1967 de la mano de Jauss. En un principio ambos conceptos, "Tradición clásica" y "Estética de la Recepción", no llegaban a

${ }^{7}$ García Jurado 2007 y 2012a.

${ }^{8}$ El origen remoto del término nace de la idea de "receptor" acuñada por K. Bühler, el psicólogo que participó en el Círculo Lingüístico de Praga, para el establecimiento de las funciones del lenguaje. Como es sabido, el Círculo lingüístico de Praga también propició los estudios formalistas en el ámbito de la literatura. 
tocarse, dado que uno pertenecía al ámbito de los Estudios clásicos y el otro al de la Teoría de la Literatura. Sin embargo, acabarían entrando en contacto a medida que los estudios sobre Recepción fueran aplicándose paulatinamente al propio objeto de estudio de la Tradición clásica.

Los presupuestos epistemológicos que sustentan ambos conceptos son, asimismo, diversos. La Classical Tradition, tal como la planteaba Highet a mitad del siglo Xx, seguía estrechamente ligada al concepto de "influencia" (como bien podemos apreciar en el subtítulo de su monografía: Greek and Roman Influences on Western Literature), y esto no resultaba una cuestión en absoluto baladí, dado que el concepto de influencia supone un "influjo" que discurre en sentido único, es decir, desde el autor más antiguo al más reciente. Bergua expone brillantemente la cuestión (las cursivas son nuestras):

La idea, o ideología si se quiere, que subyace a esta noción de influencia, es que la obra de arte, la obra literaria en este caso, es un ente vivo que despide una especie de efluvio misterioso que en el acto de la lectura alcanzaría irremisiblemente, además de a los lectores de a pie, a otros productores (escritores) y haría que sus obras se pareciesen poco o mucho a la obra en cuestión; sería algo parecido a un hechizo, o a un germen que se transmite por vía aérea. Recuérdese que en italiano 'influenza' equivale a gripe, trancazo, infección viral de las vías aéreas superiores; y es que antiguamente se pensaría que era algún tipo de efluvio maligno lo que causaba esa enfermedad. ${ }^{9}$

Desde este punto de vista, el concepto de influencia está ligado a lo que entendemos como "interpretaciones esencialistas" de la literatura, las que presuponen al texto clásico una suerte de energía interior capaz de irradiarse en los textos posteriores. ${ }^{10}$ Bergua identifica esta irradiación del sentido del texto con el pensamiento de Martin Heidegger, en particular con su teoría del des-velamiento (en griego, una de las etimologías que acaso expliquen la palabra $\alpha-\lambda \eta \dot{\eta} \theta \varepsilon \iota \alpha$, "verdad", como aquello que termina "desvelando" lo que está oculto). Heidegger de-

${ }^{9}$ Bergua 2003, p. 13.

${ }^{10}$ Bergua 2003, pp. 13-14. Las interpretaciones esencialistas, como tendremos ocasión de ver con más detalle, se oponen diametralmente a las que son fruto de la Recepción o la Intertextualidad. Mientras en la Recepción el sentido depende básicamente del lector, en la Intertextualidad tal sentido reside en la relación que los textos mantienen entre sí. 
sarrolló análogamente un pensamiento articulado en torno a la indagación de estos significados primigenios, de manera pareja a lo formulado también por Ortega. ${ }^{11}$ Esta teoría de Heidegger dejó un notable poso en la corriente hermenéutica de su discípulo Hans-Georg Gadamer, quien, a su vez, inspiraría a comparatistas de la talla de George Steiner en su idea de que los clásicos "nos leen". ${ }^{12}$ Desde este punto de vista, el texto antiguo tendría un sentido inmanente (de ahí la visión esencialista ya referida), sin menoscabo de que tal sentido deba interpretarse al cabo de los siglos conforme a su propia historicidad. Tal historicidad también ha recibido la atención de la hermenéutica de Gadamer, no en vano uno de los puntales filosóficos de la Estética de la Recepción. De hecho, en este nuevo planteamiento serían precisamente los lectores o receptores quienes pasarían a ejercer su "influencia" en la creación y estructura de determinadas obras literarias. ${ }^{13}$ De esta forma, un autor antiguo, pongamos por caso Virgilio, escribe una obra (la Eneida) con una intención determinada (la glorificación de Roma y de Augusto), pero el paso de los siglos ha dado lugar a que a esta intención vengan a añadirse nuevas lecturas o recepciones motivadas por diferentes circunstancias (el cristianismo, la palingenesia, por ejemplo) que permiten crear nuevos sentidos.

Jorge Luis Borges, en paralelo a estos planteamientos, escribió un singular cuento, "Pierre Menard, autor del Quijote", ${ }^{14}$ que ensalzaba precisamente la labor creativa del lector en calidad de autor de una "obra subterránea". Retomando la propia idea del cuento de "Pierre Menard", publicamos en 2006 un libro donde se presentaba a Borges como "autor" nada menos que de la Eneida de Virgilio. ${ }^{15}$ La Eneida borgiana no sería otra cosa que una de esas obras subterráneas, que de épica pasaría a releerse en clave elegiaca, a partir de unos cuantos versos esenciales. ${ }^{16}$

${ }^{11}$ Marías 1973, pp. 245-258.

12 Bergua 2003, p. 14.

${ }^{13}$ Estébanez Calderón 1996, s. v. "Recepción”.

14 Borges 1989a.

15 García Jurado 2006.

${ }^{16}$ Al cabo de un tiempo, durante una estancia en la Universidad de Harvard (2009), precisamente donde el propio Borges había impartido unas inmortales lecciones Norton sobre Poética, tuve la oportunidad de volver a tales versos para analizar el alcance de lo que concebí como la manera borgiana de traducir a Virgilio. Por ejemplo, el hemistiquio sunt lacrymae rerum quedaba magistralmente vertido como "Todas las cosas que merecen lágrimas" (García Jurado 2010a). 
Pero la "Eneida de Borges" sería una obra que se caracteriza, ante todo, por el hecho de haber sido leída a la luz de Beda el Venerable, de Dante, de John Milton, de Hobbes, de Croce o de T. S. Eliot. El horizonte cultural de la Eneida borgiana es más amplio o, al menos, bien distinto del que pudo tener el propio Virgilio. Tales gustos, normas o categorías literarias que los lectores van añadiendo a lo largo de la Historia constituyen el llamado "Horizonte de expectativas", que es precisamente lo que les permite contextualizar la lectura de una obra antigua en un nuevo tiempo, incluso permitiéndose el lujo de interpretar lo que el autor antiguo pudo haber dicho y acaso no dijo. ${ }^{17}$ Así pues, cuando hablamos de la "modernidad" de un autor grecolatino no dejamos de entenderlo desde nuestras propias categorías ideológicas y estéticas. Por ejemplo, cuando Michel de Montaigne pensaba en las Noches áticas de Aulo Gelio lo hacía desde una nueva perspectiva literaria que le permitía concebir la obra miscelánea latina como no-ensayo. ${ }^{18}$ Recreando una bella metáfora orteguiana, la miscelánea de Gelio vendría a ser algo parecido a la alquimia, mientras que Montaigne habría alcanzado ya la química moderna. ${ }^{19}$

Frente a la idea de "influencia", cuyo sentido transcurre desde el pasado al futuro, la Recepción implica, asimismo, la posibilidad de un sentido inverso, desde el presente (o lector) al pasado (o autor). Esta interpretación ya fue adelantada en su momento por el mismo poeta y crítico T. S. Eliot cuando habló de cómo un nuevo gran poeta podía subvertir el orden preestablecido por los autores anteriores (Eliot 1951). Borges, por su parte, materializó esta visión de la tradición literaria con su peculiar teoría de los precursores. Desde este punto de vista, los autores posteriores crearían su propia tradición eligiendo a los autores más antiguos. Así lo podemos leer en el ensayo titulado "Kafka y sus precursores", cuyo párrafo final resulta clave para entender la singular propuesta:

Si no me equivoco, las heterogéneas piezas que he enumerado se parecen a Kafka; si no me equivoco, no todas se parecen entre sí. Este último hecho es el más significativo. En cada uno de esos textos está la idiosincrasia de

${ }^{17}$ Es interesante, en este sentido, la aplicación del principle of charity utilizado por Kennedy (2006, p. 290) para el caso de la Recepción.

${ }^{18}$ García Jurado 2012b, pp. 60-61.

${ }^{19}$ Ortega 2005, pp. 18-19. 
Kafka, en grado mayor o menor, pero si Kafka no hubiera escrito, no la percibiríamos; vale decir, no existiría. ${ }^{20}$

Esta visión de la literatura rompe con cierta mecánica causal que impone la mera idea de una influencia previa. La influencia, en cualquier caso, no sería un hecho mecánico, sino, ante todo, de voluntad por parte del autor posterior, es decir, la voluntad de dejarse influir. Borges quiso, ya desde sus días adolescentes en Ginebra, dejarse llevar conscientemente por la influencia de Virgilio o, como él mismo diría, dejarse hechizar por la magia de las hipálages ("iban oscuros por entre la noche solitaria") o la polisemia de expresiones como "lento en la sombra". Bajo todo ello subyace el profundo aspecto estético que conlleva la propia Recepción desde su formulación en términos de "Estética". Ya con Benedetto Croce, a comienzos del siglo Xx, se reivindicó una lectura estética de la literatura frente a la lectura predominantemente historicista que se había llevado a cabo a lo largo del siglo XIX. El propio Borges, cuando nos habla sobre Virgilio en su fabuloso prólogo a la Eneida, se refiere a esta cuestión clave:

Diecisiete siglos duró en Europa la primacía de Virgilio; el movimiento romántico lo negó y casi lo borró. Ahora lo perjudica nuestra costumbre de leer los libros en función de la historia, no de la estética. ${ }^{21}$

Al margen de estos presupuestos, la Tradición clásica, al menos en su primera formulación, no dejaba de estar imbuida por el positivismo y el historicismo de su época. De hecho, tal como la formuló Menéndez Pelayo, se trataba de algo tan analítico como "la historia de cada uno de los clásicos en España". ${ }^{22}$ Sin embargo, desde el punto de vista de la Estética de la Recepción, como bien expresa H. R. Jauss, la reconsideración estética de la literatura implica, una revisión crítica de su propio canon:

[...] La calidad de una historia de la literatura fundada en la Estética de la recepción dependerá del grado en que sea capaz de tomar parte activa en la continua totalización del pasado por medio de la experiencia estética. Esto

\footnotetext{
${ }^{20}$ Borges 1989a, pp. 88-89.

${ }^{21}$ Borges 1996, p. 521.

${ }^{22}$ García Jurado 2012a.
} 
requiere, por un lado (frente al objetivismo de la historia literaria positivista), una canonización buscada conscientemente, la cual, por otro lado (frente al clasicismo de la investigación de la tradición), presupone una visión crítica, cuando no la destrucción del canon literario ya superado. ${ }^{23}$

Cuando Italo Calvino selecciona en Por qué leer los clásicos ${ }^{24}$ los autores antiguos que configuran su biblioteca personal, lo más destacable es el carácter sorprendente de su elección: la Odisea frente a la Ilíada, Jenofonte frente a Tucídides, Ovidio frente a Virgilio y Plinio el Joven frente a Cicerón. La perspectiva estética se justifica plenamente cuando estudiamos las sorprendentes relecturas de Ovidio desde movimientos artísticos tan distantes como el surrealismo o la recreación posmoderna. Podemos verlo en el peculiar uso que Rafael Alberti hizo de un adjetivo típicamente ovidiano, tristissima, en el contexto de uno de sus poemas surrealistas, el titulado "Noticiario de un escolar melancólico":

\begin{tabular}{|c|c|}
\hline \multirow{2}{*}{$\begin{array}{l}\text { NOMINATIVO: } \\
\text { GENITIVO: }\end{array}$} & la nieve \\
\hline & de la nieve \\
\hline DAT & la nieve \\
\hline ACUSATIVO: & a la nieve \\
\hline VO: & \\
\hline vo: & con la nieve \\
\hline
\end{tabular}

de la nieve en la nieve por la nieve sin la nieve sobre la nieve tras la nieve

La luna tras la nieve Y estos pronombres personales extraviados por el río Y esta conjugación tristísima perdida entre los árboles. BUSTER KEATON. ${ }^{25}$

La aparición final del calificativo "tristísima", así como el frío que evoca la palabra "nieve", tantas veces repetida, nos transmite el infe-

\footnotetext{
23 Jauss 2000, p. 160.

${ }^{24}$ Calvino 1993.

${ }^{25}$ Alberti 1996, p. 180.
} 
liz recuerdo que tiene Alberti de sus días escolares, cuando tuvo que aprenderse de memoria, como tantos alumnos, la más famosa elegía de los Tristes de Ovidio, precisamente la que comienza de esta manera:

Cum subit illius tristissima noctis imago,

qua mihi supremum tempus in urbe fuit $[\ldots]{ }^{26}$

El ovidiano superlativo tristissima se metamorfosea en un rasgo surrealista dentro de la poesía de Alberti, de igual forma que el virgiliano lentus in umbra de la primera bucólica se convierte en el borgiano "lento en mi sombra" del "Poema de los dones" y, más allá del tiempo y del espacio, en las "lentas filas de los panteones" dentro del temprano libro Fervor de Buenos Aires. ${ }^{27}$ ¿Influye, pues, Virgilio en Borges, o es Borges el que actualiza el lenguaje poético de Virgilio para configurar un lenguaje poético propio del siglo XX? ¿Qué pesa más, la Tradición o la Recepción? Grandes preguntas de difícil respuesta.

Así las cosas, nos encontramos ante dos etiquetas para referirse a dos maneras de ver la literatura. La "Tradición clásica" está firmemente consolidada, pero también por ello sufre las mayores críticas. Hemos visto antes cómo el término "clásico" se añadió al concepto de "tradición" gracias al filólogo Domenico Comparetti a finales del siglo XIX. ${ }^{28} \mathrm{Sin}$ embargo, la etiqueta "Recepción clásica" es muy reciente. Un simple vistazo a las publicaciones que la contienen nos remite ya al siglo XXI:

- Lorna Hardwick, Reception Studies (2003).

- Classical Receptions Journal, fundado en 2009.

- Elizabeth Vandiver, Stand in the Trench, Achilles: Classical Receptions in British Poetry of the Great War (2010).

- Hardwick \& Stray, A Companion to Classical Receptions (2011).

- Stuart Gillespie, English Translation and Classical Reception: Towards a New Literary History (2011).

Cabe observar, asimismo, que los estudiosos de la Recepción se han decantado por la formulación en plural (Classical Receptions), para re-

\footnotetext{
${ }^{26}$ Ov., Tr., 1, 3, 1-2.

${ }^{27}$ García Jurado 2015.

${ }^{28}$ Laguna 2004.
} 
ferirse al rico abanico de posibles recepciones de lo grecolatino. Por su parte, a tenor de lo que vemos en uno de los últimos manuales sobre Tradición clásica, concretamente publicado en Harvard, ${ }^{29}$ también esta disciplina ha sufrido cambios tan sustanciales que ya no cabe hablar de una sola tradición, la grecolatina, sino de varias "tradiciones clásicas". En este caso, el plural indica que lo "clásico" no concierne ya únicamente a lo grecolatino, sino a otras culturas, como la islámica, la judía o la china:

De manera ideal, este Manual no debería titularse La Tradición clásica, sino, más bien, Una Tradición clásica, dado que si algo hemos aprendido de nuestra historia reciente es que Europa es tan sólo una parte de un mundo complejo e interconectado. Tan sólo podemos comprender plenamente la herencia cultural europea cuando la situamos en el contexto más amplio de otras culturas con las que ha estado siempre en diálogo. La Tradición clásica grecorromana no es más que una de la tradiciones clásicas concretas que definen la historia de la cultura universal, y sus cruciales afinidades y divergencias con otras tradiciones clásicas, tales como la islámica, la judaica, la china o la india, implica que no puede ser realmente entendida sin una referencia sistemática a éstas. ${ }^{30}$

De esta forma, nos encontramos con la sorpresa de que los respectivos plurales de cada etiqueta, a saber, Classical Traditions y Classical Receptions, no hacen un mismo uso del adjetivo Classical, pues en el primer caso debemos pensar en la multiplicidad de las posibles culturas "clásicas" y, en el segundo, debe contemplarse la riqueza de recepciones de la cultura clásica como tal, independientemente del tiempo y lugar donde tenga lugar tal recepción. Queda abierta, asimismo, la posibilidad de llevar a cabo estudios de "tradiciones clásicas" comparadas y sus mecanismos de recepción. En este sentido, la multiplicidad de culturas clásicas en Iberoamérica favorece el estudio de la incorporación de ciertos mitos antiguos en obras literarias modernas: es el caso del mito platónico de Theuth en Cien años de soledad de García Márquez, de igual forma que los los mitos mayas del Popol Vuh alimentan la obra del guatemalteco Miguel Ángel Asturias. Se cuestiona, pues, la existencia de una única Tradición clásica y hasta se duda sobre la pertinencia de

\footnotetext{
${ }^{29}$ Grafton, Most y Settis 2010.

${ }^{30}$ Ibid., p. X. Trad. de García Jurado.
} 
hablar de Tradición clásica grecolatina. En este sentido, los partidarios de la Recepción clásica hablan abiertamente del sentido problemático del término "Tradición". 31

No creemos estar, por tanto, tan sólo ante visiones complementarias del mismo hecho, sino en franco conflicto. Quizá el aspecto clave resida precisamente en el planteamiento jerárquico de la Tradición clásica frente a la desjerarquización del autor clásico con respecto al moderno, o el llamado democratic turn, que vendría a definir los estudios de Recepción frente al sentido jerárquico que aún en los años 50 seguía revistiendo el uso de un adjetivo como "clásico" (recordemos que en la antigua Roma classicus se oponía a proletarius, García Jurado 2010b). Aquí puede verse una clara oposición a consideraciones jerárquicas sobre la idea de lo que es un clásico, propias de autores como T. S. Eliot (1951) en los años 30 del siglo XX, donde la superioridad de un autor como Virgilio estaba fuera de toda duda, frente a planteamientos que entran mejor en la llamada "corrección política", incluso por encima de aspectos puramente literarios. Veamos de forma más concreta en qué consiste el llamado "giro democrático" que caracteriza a la Recepción:

El "giro democrático" afecta a una serie de aspectos [...]. En primer lugar, se cuestionan las presuposiciones sobre la inherente superioridad de las obras antiguas y se considera la condición y calidad independiente de la obra moderna [...]. En segundo lugar, la investigación ha rastreado caminos por los que (en parte, gracias a la educación) los grupos sociales menos favorecidos han accedido a un mejor conocimiento tanto de las obras antiguas como de las modernas, donde a veces estas últimas sirven como introducción a las primeras. En tercer lugar, el alcance de las formas y discursos artísticos que utilizan o reconfiguran el material clásico se ha extendido incluso a la cultura popular. ${ }^{32}$

Este resultado de nivelación no dejaría de ser, lejanamente, una vuelta de tuerca más a lo que en entre los siglos XVII y XVIII se denominó como la "Querella de los Antiguos y los Modernos". Pero no podemos tampoco dejar de ver en esta actitud una postura política que va más allá

31 "One reason for this focus on the well established is the fact that the concept of «tradition» is both epistemologically and politically problematic" (Budelmann y Haubold 2008, p. 24).

${ }^{32}$ Hardwick \& Stray 2011, p. 3. Trad. de García Jurado. 
de lo estrictamente literario hacia una democratización de los gustos, al tiempo que se traza una especie de camino inverso por el que las manifestaciones artísticas más modernas pueden convertirse en una suerte de introducción a los clásicos, desde las periferias. Como antes veíamos al hablar sobre la estética, la desjerarquización también tiende a reformular el canon. El canon, como ya veíamos en la referencia que hicimos a Italo Calvino, parece definirse más bien en términos personales y a partir de unas claves vitales que dejan al margen la discutible cuestión de la superioridad de unos autores sobre otros. Es significativo, a este respecto, lo que afirmaba en una entrevista Francisco Rico a propósito de la enseñanza de las humanidades:

- ¿Y qué reforma educativa considera más urgente?

- Quizá reformular el canon de las humanidades, de manera que Virgilio no parezca más relevante que Borges, y adaptar su enseñanza a los nuevos modos de percepción y de conocimiento que se están desarrollando de acuerdo con los nuevos medios. ${ }^{33}$

De esta forma, desde el punto de vista conceptual, podemos decir sucintamente que "Tradición clásica" y "Recepción clásica" no son términos equivalentes. Su diferente antigüedad, la diversa función que desempeña el adjetivo "clásica" en cada uno y, sobre todo, sus diferencias epistemológicas los convierten en puntos de vista dispares. Por lo demás, la etiqueta "Tradición clásica", si ya suponía una restricción de sentido, no ha dejado de reformularse hasta el presente: las refecciones "Tradición clásica grecolatina" y "Tradiciones clásicas" son buenas muestras de este estado de cosas.

\section{Entre la Tradición y la Recepción clásicas. Cuestiones históricas}

Como ya hemos señalado, la "Tradición clásica" tuvo que formularse con esta etiqueta cuando otras dos grandes formas de tradición irrumpieron en el horizonte cultural de la segunda mitad del siglo XIX: de un lado, la ya citada "Tradición popular", que convirtió a lo "clásico" en sinónimo de "culto" y, de otro lado, las nuevas formas literarias

\footnotetext{
${ }^{33}$ Azancot 2010.
} 
alternativas al clasicismo, como la romántica y la decadente, que intentaban romper con la propia tradición académica. Finalmente, como bien apunta Octavio Paz en Los hijos del limo, ${ }^{34}$ esta ruptura con la Tradición (clásica) terminó convirtiéndose en una "Tradición de la ruptura" que, de manera paradójica, inició un nuevo diálogo con los propios clásicos grecolatinos. Así las cosas, como ya hemos establecido en otro lugar, se puede hablar de tres períodos básicos para entender la historia de la disciplina que conocemos como Tradición clásica. Merece la pena que los recordemos aquí:

-Primera etapa (a partir de 1872): de la "Tradición" a la "Tradición clásica". - Segunda etapa (a partir de 1949): la "Tradición clásica" como relato.

- Tercera etapa (a partir de 1979): la "Tradición clásica (grecolatina)" frente a la "Recepción".

Podemos hablar perfectamente de una primera etapa de formación, dominada por el método positivista e histórico que llega hasta las figuras de Ernst Robert Curtius y Gilbert Highet. Domenico Comparetti o Menéndez Pelayo son buenos exponentes de los albores de esta primera etapa caracterizada por el método que se define como "A en B". Precisamente, fue Menéndez Pelayo el primero en utilizar la etiqueta "Tradición clásica" en lengua española, dentro de un pasaje de su Historia de los heterodoxos españoles (publicada entre 1880 y 1881, es decir, ocho años más tarde que el Virgilio nel medioevo de Comparetti):

Tuvo que venir la férrea y bienhechora mano del Santo Oficio a destruir en el siglo XvI estos resabios del paganismo [...] ; Tanta fuerza tuvo en los pueblos latinos la Tradición clásica, que algunos suponen destruida y cortada en los tiempos medios! $!^{35}$

Como podemos ver, el contexto identifica claramente la "Tradición clásica" con el mundo pagano ("resabios del paganismo") y cuestiona una interrupción de esta tradición durante la Edad Media. Esta postura creó una suerte de dicotomía entre los partidarios de la interrupción histórica y los partidarios de una continuidad cultural de lo clásico du-

${ }^{34}$ Paz 1993, p. 18.

${ }^{35}$ Menéndez Pelayo 1946-48, II, p. 429. 
rante la Edad Media. ${ }^{36}$ La propia acuñación historiográfica de "Renacimiento" (la Renaissance concebida en términos absolutos y con mayúscula, a la manera de lo que hizo el historiador de la cultura Jakob Burckhardt) crea la metáfora de un mundo clásico que habría fenecido a finales de la Antigüedad y "renacería" con los primeros humanistas. A esta lectura de la interrupción medieval del legado clásico salió al paso un reconocido romanista alemán, Ernst Robert Curtius (1989), al reivindicar en su Literatura europea y Edad Media latina (publicada como libro en 1948) una continuidad que desde el mundo clásico pasaba por la propia Edad Media hasta nuestros tiempos modernos. Esta idea de continuidad cultural e histórica se convierte en un elemento clave para la Tradición clásica, a diferencia de lo que ocurre con la Recepción, dado que ésta no precisa tanto de la continuidad. Sin embargo la Tradición requiere de una continuidad basada, por ejemplo, en la presencia de los estudios clásicos dentro de la escuela. Así lo hemos comprobado en nuestros recientes estudios sobre la lectura de la primera bucólica de Virgilio que hacen Eça de Queiroz, Antonio Machado y Jorge Luis Borges. A veces, cuando no existe una tradición, se puede inventar, o incluso reconstruir una trama rota, como la que plantea cierta literatura moderna compuesta por escritoras como Sor Juana Inés de la Cruz. ${ }^{37}$ La Recepción, por su parte, bien podría no requerir de tales continuidades históricas y constituirse en cualquier momento y lugar gracias simplemente a algunas circunstancias especiales que la hagan posible. Hemos tenido ocasión de reflexionar acerca de este hecho al observar cómo en la cultura japonesa se transmiten de generación en generación los usos religiosos sintoístas y budistas, mientras los elementos de la cultura grecolatina que hemos encontrado podrían ser a menudo simples fenómenos de recepción, donde el significante aparece en más de una ocasión desposeído de su sentido primigenio. Es el caso, por ejemplo, de una escultura de las Tres Gracias que encontramos en Hiroshima, junto a un edificio que prácticamente estaba situado bajo el lugar donde había caído la bomba atómica en 1945. Cabía preguntarse aquí qué función tenía esa escultura más allá de lo meramente decorativo o un vago y lejano aroma europeo:

\footnotetext{
${ }^{36}$ García Jurado 2014.

37 González 1999.
} 


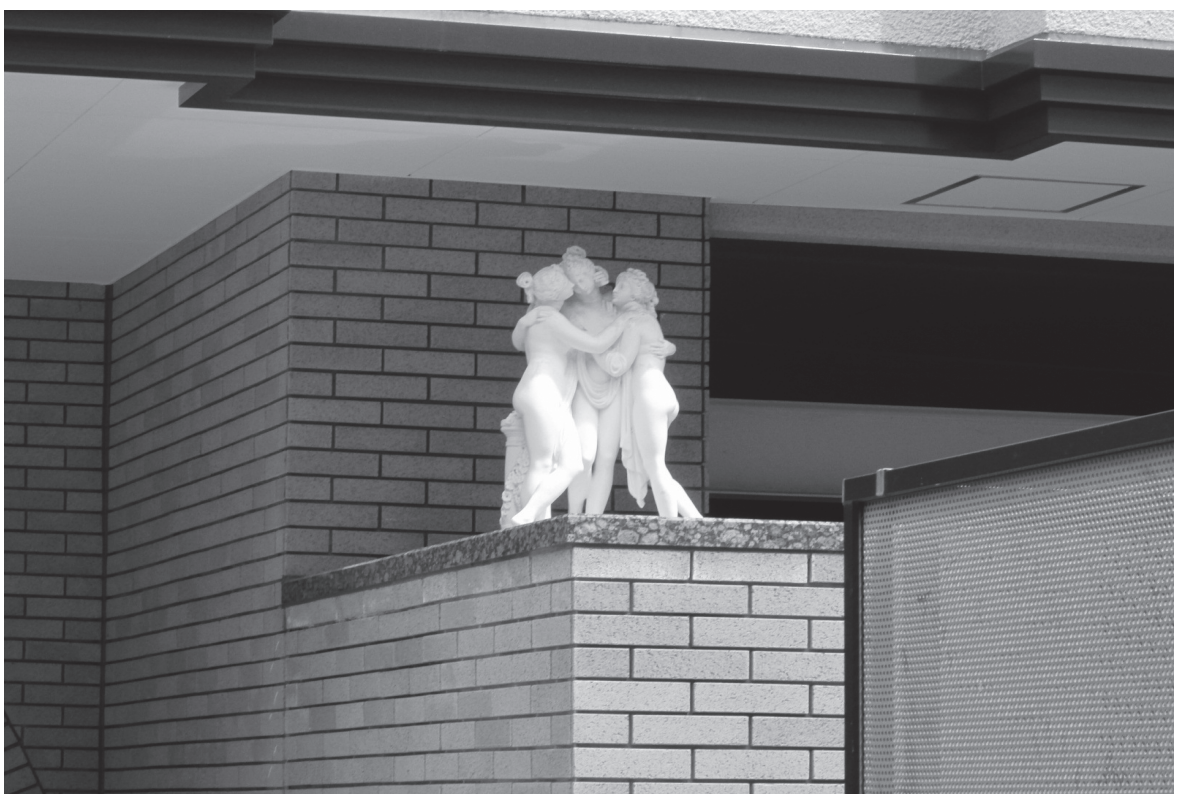

Estatua decorativa de las Tres Gracias (Cárites) en un edificio del centro de Hiroshima.

Fotografía de F. García Jurado

Lo cierto es que tampoco en la propia Europa, salvo los especialistas en Mitología clásica o Bellas Artes, sabemos que tales figuras corresponden a las hijas de Zeus y la ninfa Eurínome, hija, a su vez, del titán Océano, y mucho menos que sus nombres son Áglaye, Eufrósine y Talía. Como mucho, se las puede identificar con pinturas como la famosa de Rubens que se conserva en el madrileño Museo del Prado. En cualquier caso, la tradición iconográfica en el arte bien puede constituirse en una forma tácita de Tradición. Así, la primera etapa de la Tradición clásica vino caracterizada por este afán de asegurar un continuum cultural en un momento en que la modernidad y sus rupturas comenzaban a irrumpir violentamente dentro del panorama de la literatura y las artes.

La segunda etapa de la Tradición clásica viene marcada por el conocido libro de Highet, que contribuye a consolidar la disciplina y a conferirle la forma de un relato global, en otras palabras, de una Historia de la literatura, más allá de los meros estudios particulares. Este cambio resulta muy significativo, pues normalmente la disciplina se había caracterizado por cierta atomización (un autor antiguo "en" un autor o 
literatura modernos). Se suponía que la suma de los estudios particulares daría lugar a la historia global, sin atender al hecho de que ciertas propiedades no pueden apreciarse si no es desde una perspectiva conjunta. No obstante, con todas las posibles críticas y carencias, fue Highet quien acometió esta singular empresa de llevar a cabo una Historia literaria de la Tradición clásica. De esta forma, la aceptación o el rechazo de este gran manual, con la reseña crítica de María Rosa Lida (1975) a la cabeza, es lo que ha presidido toda esta segunda etapa que se extiende hasta finales de los años 70, precisamente cuando vayan apareciendo métodos de estudio alternativos al del historicismo. De manera particular, los últimos dos decenios del siglo XX y primero del XXI han dado lugar al cuestionamiento de ciertos conceptos muy asentados en el ámbito académico de la Tradición clásica, como los de "fuente" o "influencia", con la correspondiente entrada de nuevos métodos en el ámbito de los estudios de Tradición clásica, entre los que cabe destacar los estudios de Recepción y la Intertextualidad.

La Recepción vendría a ser uno de los métodos que aparecen en el nuevo contexto de los estudios sobre Tradición y es un fenómeno que coincide en el tiempo con el tercer período establecido más arriba. Jauss, por su parte, también había historiado las etapas del estudio de la literatura utilizando un término común entre los historiadores de la ciencia: el de "paradigma". Según ello, Jauss establecía tres paradigmas posibles: ${ }^{38}$

-El clásico-humanista, dominado por la imitación de los textos clásicos

-El histórico-positivista, propio de los siglos XIX-XX, dominado por la idea de las literaturas nacionales

-El estético-formalista, tras la Primera Guerra Mundial, dominado por la estilística

Jauss anunciaba los indicios de un nuevo paradigma orientado hacia la hermenéutica filosófica de la que ya hemos hablado más arriba. $\mathrm{Cu}$ riosamente, la Tradición clásica, según este esquema histórico de Jauss, se habría conformado dentro del paradigma histórico-positivista, una vez desaparecido el paradigma de la imitación humanista. Sólo al cuestionarse este primer paradigma fue cuando hubo que crear una disciplina de carácter histórico que pudiera estudiar el fenómeno de la influencia

${ }^{38}$ Iglesias Santos 1994, pp. 39-40. 
de los clásicos grecolatinos en la literatura europea. Por lo demás, las aproximaciones estético-formalistas no calaron mucho en la disciplina, pues las reflexiones más importantes en este sentido se hacen fuera de ella, desde T. S. Eliot (1951) a Harold Bloom (1991) o Claudio Guillén (2005).

Al margen de tales presupuestos, el historicismo y la visión causal de la Tradición han seguido constituyendo el método defectivo de la Tradición clásica hasta nuestros días. Tal método está basado en la polaridad a que da lugar el doble desarrollo etimológico de la palabra latina traditio, es decir, la solución culta, "tradición", y la vulgar, "traición”. Desde el punto de vista más estricto, la primera sería una acepción positiva y la segunda negativa. Sin embargo, Bloom (1991) considera que son precisamente las "traiciones", concebidas como malentendidos (misunderstandings), las que van a conferir creatividad a las nuevas recepciones de los autores clásicos. Leamos, a manera de ejemplo, unos interesantes versos de Borges:

La amistad silenciosa de la luna

(cito mal a Virgilio) te acompaña. ${ }^{39}$

De manera explícita, Borges está citando o recreando un verso de la Eneida, en particular tacitae per amica silentia lunae (2, 255), literalmente: "por entre los amistosos silencios de la tácita luna". El énfasis virgiliano en las palabras que designan el silencio aparece rebajado de diferentes maneras en la "cita errónea" de Borges:

-Los "amistosos silencios" se convierten en la "amistad silenciosa", de forma que el plural pasa a singular y las palabras intercambian sus papeles como adjetivo y sustantivo.

- Borges evita lo que en español suena al pleonasmo de la "luna silenciosa" o "tácita".

Todo ello, en especial la propia conciencia de "citar mal a Virgilio", convierte esta "traición" en "recepción creativa", dado que la supuesta irradiación del texto clásico se puede ver "adulterada" o "recreada", dependiendo del punto de vista del lector, que cuando se convierte en

${ }^{39}$ Borges 1989b, p. 339. 
autor puede sentirse, asimismo, tentado o perseguido por la idea de originalidad. Es de esta forma, en definitiva, como se termina sintiendo el personaje del cuento "Parturient montes" escrito por Juan José Arreola. Ante el reclamo general de que realice una nueva versión de la fábula del parto de los montes, el pobre poeta termina representando el parto mismo de un pobre ratón, acaso el originario. ${ }^{40}$

Estas nuevas propuestas metodológicas han ido calando de desigual manera en el propio ámbito de los estudiosos de la Tradición clásica, que en gran medida siguen afincados en el viejo método positivo que se define como "A en B". La incipiente irrupción de un cuarto paradigma, el de la Recepción, ha creado, por su parte, una tensión entre dos formas de entender el mismo hecho.

\section{Entre la Tradición y la Recepción clásicas. Cuestiones de método}

Ya venimos adelantando que son bien diferentes los métodos que han sustentado los nacimientos de los estudios de "Tradición" y "Recepción”. Mientras que para la Tradición clásica el método primero fue, como no podía esperarse menos, el positivismo e historicismo imperantes a finales del XIX y comienzos del XX (el llamado método "A en B": "Horacio en España"), los estudios de Recepción se han visto legitimados por la hermenéutica de la lectura y su historicidad. Un repaso atento de los principios que definen la publicación oxoniense del Classical Receptions Journal puede arrojar algunas claves acerca del planteamiento que preside estas investigaciones (las cursivas son nuestras):

La revista Classical Receptions abarca todos los aspectos de la recepción de los textos y la cultura de la antigua Grecia y Roma desde la Antigüedad hasta el presente. Su propósito es explorar las relaciones entre transmisión, interpretación, traducción, transplante, reescritura, reelaboración y replanteamiento del material grecorromano dentro de otros contextos y culturas. Se abordan las implicaciones tanto para los nuevos contextos de recepción como para los antiguos, y se comparan diferentes modalidades de interacciones lingüísticas, textuales e ideológicas. ${ }^{41}$

\footnotetext{
40 García Jurado 1998-99.

${ }^{41}$ Fuente: <http://crj.oxfordjournals.org>. Trad. de García Jurado.
} 
Los Classical Reception Studies contemplan, en este sentido, cualquier forma de lectura del mundo clásico desde la Antigüedad al presente. Llama la atención el uso de la expresión "Greek and Roman material", que encontramos, asimismo, en la propia definición que de "Recepciones" nos dan Hardwick y Stray en su manual:

Por "recepciones" nos referimos a las maneras en que la materia griega y romana ha sido transmitida, traducida, extractada, interpretada, reescrita, reimaginada y representada. Hay actividades complejas donde cada "hecho" de recepción es, asimismo, parte de procesos más amplios. Las interacciones se combinan con una sucesión de contextos, ya de naturaleza clásica o no clásica, para producir un panorama donde a menudo nos aguardan desniveles inesperados, con sus subidas y bajadas, apariciones y supresiones y, a veces, metamorfosis. Es por ello por lo que el título de este volumen se refiere a las "recepciones" en plural. ${ }^{42}$

Lo fundamental de los dos textos citados es la idea de cómo el "material grecorromano" puede reelaborarse o reciclarse, frente a la metáfora de carácter ontológico sobre la que se sustenta la idea más primigenia de Tradición clásica, es decir, la idea de un legado inalterable que se transmite esencialmente en calidad de tal legado. Frente a ello, la metáfora de la metamorfosis o reciclado implica esencialmente la transformación o adulteración, en especial para los que velan por la fidelidad de lo transmitido. Todo esto tiene unas implicaciones muy notables, incluso en el propio método de trabajo. El esquema de un estudio de Tradición clásica concebido desde el método positivo tiene como aspecto fundamental la "búsqueda de fuentes" (Quellenforschung). En este sentido, el estudio de un mito clásico en un autor moderno dedicaría gran parte de sus esfuerzos al análisis mitográfico, en especial al rastreo de las fuentes grecolatinas de tal mito. Es el caso, por ejemplo, de lo que puede ocurrir en un estudio sobre el mito de Teseo en la poesía española moderna (precisamente, el tema de la tesis doctoral de Hernández Henríquez (2010), de cuyo tribunal hemos formado parte). Desde una perspectiva metodológica conservadora, se haría un exhaustivo estudio de las fuentes grecolatinas para luego valorar cómo los poetas modernos han interpretado de manera más o menos fiel tales fuentes. Ahora bien, en lo que respecta

${ }^{42}$ Hardwick \& Stray 2011, p. 1. Trad. de García Jurado. 
a este mito de Teseo en concreto, resulta que hay un artista y un autor modernos que van a convertirse igualmente en referentes de inspiración, junto a los propios autores de la Antigüedad. Nos referimos al tratamiento que Pablo Picasso hizo sobre el Minotauro y a Jorge Luis Borges, que invirtió la perspectiva del mito desde Teseo al propio Minotauro en su cuento titulado "La casa de Asterión". De esta forma, la frontera entre "fuentes antiguas" y "receptores modernos" se vuelve borrosa a la hora de estudiar ciertas recepciones modernas, dado que parte de esa nueva recepción puede acabar convirtiéndose en nueva fuente. Esta suerte de reelaboración de lo ya reelaborado entraña, a su vez, el peligro de que nos interesemos exclusivamente por ese producto final. De esta forma, la Recepción no encuentra problema alguno en considerar su principal objeto de estudio la obra moderna, al margen del diálogo que ésta pueda mantener con los clásicos. En algunos casos, tal como ocurre en ciertos montajes teatrales inspirados lejanamente en un autor clásico, puede darse la situación extrema de que tal autor no sea más que un pretexto. "Sobra Eurípides" era el título de una reseña escrita por el crítico teatral Eduardo Haro Tecglen para comentar un montaje que Salvador Távora había realizado supuestamente a partir de Las bacantes:

Olvidemos a Eurípides. No es fácil: desde el título hasta algunas palabras, nombres propios, situaciones, vestuario, nos están diciendo en este espectáculo que lo que se representa es Las bacantes. Si lo aceptamos, todo esto es un desastre: una pedantería, un esnobismo, una forma de agarrarse a una forma intelectual ajena y de vender la gloria de otro. Si olvidamos a Eurípides, queda un bello espectáculo andaluz $[\ldots]^{43}$

Podemos estar ante un caso de lo que cabría denominarse como "Tradición no figurativa", dado que la forma de la obra moderna resalta tanto que oculta la materia antigua. No obstante, si gracias a esta perspectiva discurrimos desde las obras modernas hasta las antiguas, nos encontramos con la paradoja de cómo hay aspectos de la Antigüedad que hoy día llegan al gran público por medio de manifestaciones artísticas consideradas como "periféricas". Así ocurre con ciertos cómics inspirados en la Antigüedad. Cabe la posibilidad de que, en una época donde la gran literatura parece haber sido barrida, alguien pueda sentir el interés de lle-

\footnotetext{
${ }^{43}$ Haro Tecglen 1987.
} 
gar, pongamos, desde una película como Incendies ${ }^{44}$ a la propia tragedia Edipo rey de Sófocles, que le sirve de profunda inspiración. Este camino de regreso es, sin embargo, incierto.

Por tanto, si los estudios de Tradición clásica requerían, al menos en su formulación más primigenia, de verdaderos especialistas en las fuentes literarias de la Antigüedad, ${ }^{45}$ la Recepción puede congregar en la práctica a personas con un conocimiento endeble o casi nulo de la literatura clásica. ${ }^{46}$ Desde nuestro modesto punto de vista, lo que en una disciplina (la Tradición clásica) puede revestir el carácter de un minucioso exceso, en la otra (la Recepción) acaso se convierta en asunto irrelevante y prescindible, frente al hecho de la reelaboración convertido en el verdadero objeto de estudio. Esta circunstancia ha dado lugar a que ciertos géneros, como la moderna poesía lírica o el teatro, ocupen en este momento un especial interés para la Recepción gracias a las grandes transformaciones que la "materia clásica" ha podido sufrir durante un proceso donde tal materia prima puede terminar siendo prácticamente irreconocible.

Si la Tradición clásica partía en su formulación más primigenia de la metáfora ontológica del "legado" como objeto material que se transmite por medio de la "influencia", las investigaciones en torno a la Recepción se acercan más a la dualidad de tipo aristotélico que considera tanto lo griego como lo latino una mera "materia", lo que permite que observemos las nuevas "formas" que tal materia adquiere en contextos lejanos en el tiempo y el espacio. Hay, por tanto, dentro de la Recepción un énfasis decidido en la transformación o incluso "reciclado" que implica la moderna asimilación de diversos aspectos de la Antigüedad, al margen de lo sui generis que pueda resultar tal recepción. En este sentido, nos llamó la atención el peculiar estilo "clásico" (por llamarlo de alguna manera) que presentaba el edificio japonés donde se alberga el observatorio del monte Fuji:

${ }^{44}$ Denis Villeneuve 2010.

45 Pensemos en helenistas de la talla del australiano Gilbert Murray o, en el caso hispano, de excelentes conocedores de la literatura griega como el mexicano Alfonso Reyes.

${ }^{46} \mathrm{Al}$ menos, esa es nuestra experiencia, a tenor de lo visto en algunos congresos europeos. 


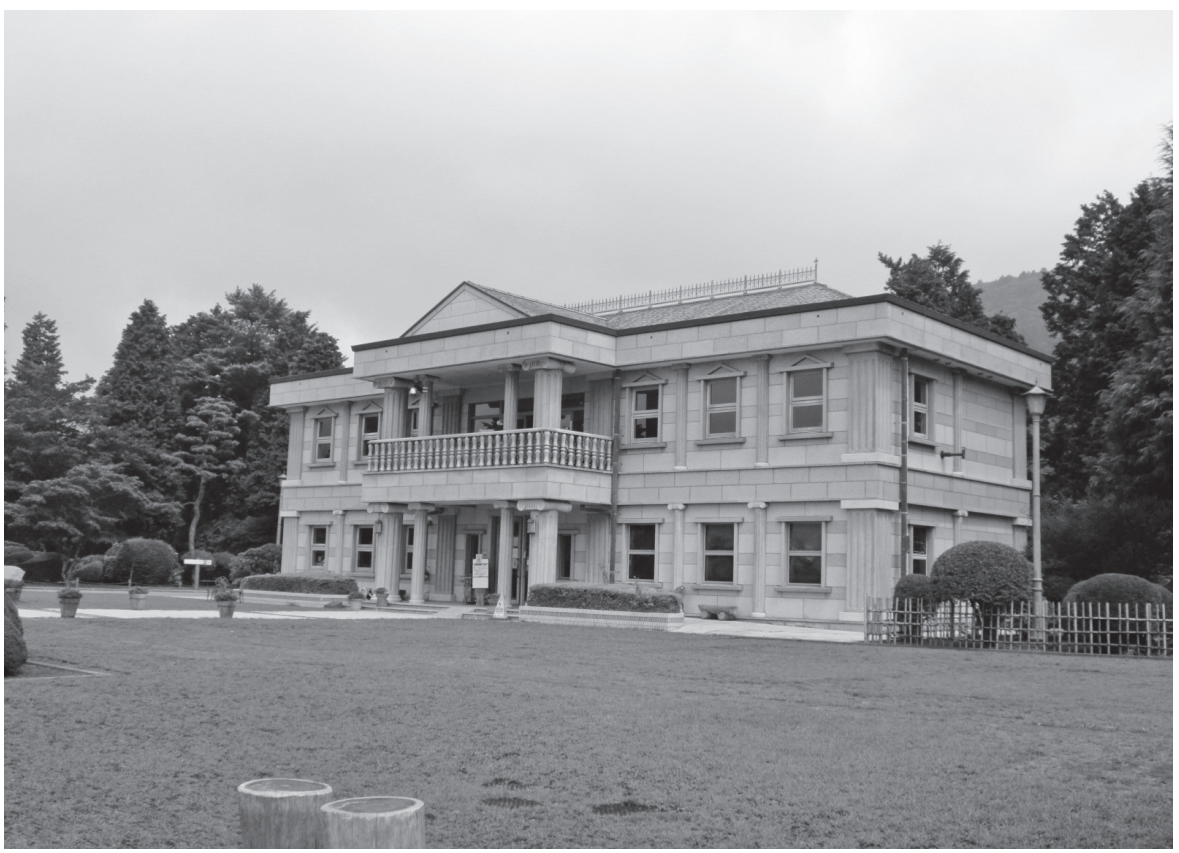

Peculiar estilo clásico del Observatorio del Monte Fuji (Japón).

Fotografía de F. García Jurado.

Si bien el edificio respeta la clásica idea de simetría, la buscada desproporción que podemos apreciar entre las columnas (¿jónicas?) resulta ya absolutamente anticlásica.

Los estudiosos de la Tradición clásica no han recurrido, salvo en casos puntuales y casi excepcionales, a considerar de una manera razonada las nuevas aportaciones de la Intertextualidad, a pesar de lo productivas y útiles que resultan. El peso del método positivo y cierta inercia irreflexiva con respecto a los procedimientos tienen que ver en este hecho. Sin embargo, esta ausencia de lo intertextual resulta más significativa, si cabe, en los estudios sobre Recepciones clásicas, dado su carácter moderno y más preocupado por las propias cuestiones hermenéuticas. Curiosamente, la Intertextualidad, debido a su énfasis en las propias relaciones entre textos, comparte con los estudios de Recepción una concepción no esencialista de la literatura. Como bien expuso Claudio Guillén en los años 80 del pasado siglo Xx, la Intertextualidad viene a renovar profundamente conceptos tan arraigados como los de "influen- 
cia" o "fuente". ${ }^{47}$ La fuente literaria pertenece, sobre todo, a una concepción esencialista del texto, donde el texto antiguo existe por sí mismo y no precisa de otros textos para alcanzar su sentido pleno. La Intertextualidad, desde presupuestos claramente deudores del estructuralismo, niega este principio al concebir que la naturaleza de los textos depende precisamente de las relaciones que puedan crearse entre ellos, de donde provienen las diferentes modalidades de Intertextualidad. De esta forma, debemos decir que, desde una perspectiva epistemológica, una "fuente literaria" no es un "intertexto" ("hipotexto" o texto subyacente, expresado de manera más precisa), aunque ambos conceptos puedan coincidir en designar una misma realidad. ${ }^{48}$ Pocos poemas, como el que Borges tituló "Elegía", ejemplifican mejor el concepto de "expansión del hipotexto". En torno a un verso de Virgilio, sunt lacrymae rerum, et mentem mortalia tangunt (Aen., 1, 462), Borges desarrolla a la manera de una enumeración caótica (lo que no deja de ser un perfecto guiño posmoderno de universo abierto), todo el potencial de la palabra latina res:

Sin que nadie lo sepa, ni el espejo, ha llorado unas lágrimas humanas.

No puede sospechar que conmemoran todas las cosas que merecen lágrimas:

la hermosura de Helena, que no ha visto, el río irreparable de los años, la mano de Jesús en el madero de Roma, la ceniza de Cartago, el ruiseñor del húngaro y del persa, la breve dicha y la ansiedad que aguarda, de marfil y de música Virgilio, que cantó los trabajos de la espada, las configuraciones de las nubes de cada nuevo y singular ocaso y la mañana que será la tarde.

Del otro lado de la puerta un hombre

${ }^{47}$ Guillén 2005, p. 287.

${ }^{48}$ Lo que Genette (1989) llamó "hipotexto" no equivale al término "fuente". El primer término pertenece a una concepción estructural de la literatura, mientras el segundo es fruto del positivismo del siglo XIX. El hipotexto no es un texto físico, sino mental, y muestra unas características dinámicas (frente al texto fijado de antemano y por escrito). 
hecho de soledad, de amor, de tiempo, acaba de llorar en Buenos Aires todas las cosas. ${ }^{49}$

En este poema subyace, y así creemos haberlo demostrado fehacientemente en otro lugar, ${ }^{50}$ el citado verso de Virgilio, pero aún más importante es apreciar, asimismo, su capacidad de expansión a la hora de configurar el poema. Cabría preguntarse dónde está, materialmente, el verso de Virgilio en la composición. Es cierto que el verso subyace en "todas las cosas que merecen lágrimas", pero no está menos presente en otros lugares del poema. La cuestión nos recuerda a lo que Platón se planteaba en su diálogo La República con respecto a los juicios analíticos: cuando sumamos uno más uno, dónde están luego estos números en la síntesis del dos. Este es el problema del texto subyacente, o del hipotexto, que en realidad ya no existe como tal texto, dado que pasa a ser una especie de materia prima que se metaboliza en el nuevo poema para convertirse en una suerte de proteína literaria. De esta forma, cada vez nos parece más ilusoria la metáfora de la "fuente", que presupone la presencia material del texto previo en el texto posterior. Por ello, cuando indagamos en los hipotextos virgilianos que aparecen en Borges podemos encontrar tantas mutaciones o "traiciones". Muchos especialistas han hecho un uso abusivo del término "hipotexto" sin saber realmente de su condición inmaterial. Lo han considerado como un mero sinónimo de "fuente", simplemente una forma más moderna de renombrar esta vieja etiqueta de regustos positivistas.

Recepción e Intertextualidad vienen a coincidir, desde presupuestos diferentes, en una consideración relativista del texto, frente al esencialismo. Sin embargo, cabe preguntarse si todo es tan relativo como para que el valor de un texto clásico dependa básicamente de su recepción lectora o de la relación con otros textos. Así las cosas, sabemos que no todos los textos antiguos son merecedores de la misma lectura moderna o complejidad de relaciones. Al margen de sus posibles transformaciones o relecturas, algo debe de tener ese texto antiguo para que se haga digno de semejante relectura. A veces, incluso la mala traducción de un gran texto sigue conservando aspectos fundamentales de su primitiva grandeza. En

\footnotetext{
49 Borges 1989b, p. 309.

${ }^{50}$ García Jurado 2010a, pp. 298-299.
} 
este sentido, entre el sentido primigenio y su interpretación moderna, cabe apelar a ciertos valores inmanentes de este texto antiguo no tanto de una manera esencialista como puramente formal. Aquí es oportuno revisar la interesante propuesta que hace Miguel Alarcos ${ }^{51}$ a la hora de combinar la Intertextualidad con el concepto lingüístico de la "inmanencia”, procedente de la glosemática y de la propia lingüística que, a partir de esta escuela, desarrolló asimismo su padre, Emilio Alarcos. Miguel Alarcos denomina este fenómeno en términos de "inmanencia intertextual", y se puede apreciar cuando estudiamos la transformación obrada en las estructuras del propio texto antiguo para considerar qué funciones termina desarrollando tal texto dentro de la nueva obra. Sin salir del ámbito del poema borgiano antes citado, la concisión extrema de la palabra res en el verso virgiliano se transforma ahora en una enumeración caótica dentro de la nueva poética, pero este cambio de función no nos impide reconocer los vínculos entre ambos textos. En el hecho intertextual cabría hallar dos planos, a saber: la asimilación del texto previo en el propio universo borgiano y la reelaboración de este texto a partir del hipotexto virgiliano o "material en estado bruto". De manera funcional, este hipotexto pasaría a desempeñar nuevas funciones en el nuevo contexto literario. Debido a esta posición intermedia, la noción de "intertexto" supone un buen vínculo entre la Tradición y la Recepción, o entre los conceptos de "fuente" y de "material".

\section{Conclusiones}

La disciplina que conocemos como Tradición clásica presenta una naturaleza dinámica y polémica, y no sólo desde el punto de vista académico. Es difícil establecer unas conclusiones ante un tema tan complejo y, a la vez, tan lábil. Sobre todo es difícil concluir cuando las preguntas que nos hemos planteado son mucho más interesantes que las posibles respuestas. La gran pregunta, en cualquier caso, tiene que ver con la naturaleza de la relación que se plantea entre las literaturas antiguas y su diálogo con las modernas.

Desde el punto de vista conceptual, hemos visto cómo "Tradición clásica" y "Recepción" responden a claves bien distintas, tanto en el tiempo

${ }^{51} 2014$, pp. 30-31. 
como desde el punto de vista de los planteamientos que sustentan cada etiqueta. La etiqueta "Tradición clásica" nació como una restricción de sentido debido a su carácter culto (que la opone a la "Tradición popular") y "antiguo" (que la opone a la "Tradición moderna"). La posterior polaridad entre "Tradición" y "Recepción" resulta ya muy reciente. En cualquier caso la Tradición clásica sigue unida a la idea de "influencia" e "historicismo", mientras que la Recepción clásica se sustenta en la idea del lector como creador y de la lectura estética. Asimismo, el uso plural en ambas etiquetas también responde a ideas diferentes. Las "Tradiciones clásicas" son fruto de una nueva restricción de la etiqueta, en el sentido de que ya no sólo habría una sola Tradición clásica, la grecolatina. Las "Recepciones clásicas" se refieren, sobre todo, a la multiplicidad que revisten nuestras relecturas de lo grecolatino. Asimismo, la Recepción se caracteriza por la desjerarquización, o "giro democrático", por lo que resulta tan importante la obra receptora como la originaria.

La historia de ambas disciplinas muestra, asimismo, una desproporción en el tiempo. Tres etapas marcan el desarrollo de la "Tradición clásica": una de conformación, marcada por el positivismo metodológico y el historicismo, donde hay una especial preocupación por la idea de continuidad histórica del legado clásico; otra segunda de consolidación y crítica, a partir de la publicación en 1949 del libro de Highet, que es cuando se crea un discurso histórico global; finalmente, otra tercera de reformulación, sobre todo ante la irrupción de los estudios de Recepción, que consideran las "recepciones" como hechos creativos (transformaciones) más que meramente hereditarios.

Desde el punto de vista de los métodos, la Tradición clásica no ha sido todo lo permeable que hubiera resultado oportuno a las nuevas aportaciones y, en especial, al cuestionamiento del concepto de "fuente" literaria. La Recepción parte de la idea de que el "material grecorromano" puede ser transformado y reciclado, de forma que encuentre nuevas formas. Creemos, no obstante, que se ha perdido y sigue perdiendo una gran oportunidad al obviar las aportaciones de la teoría intertextual, así como conceptos que pueden resultar muy útiles a la hora de encontrar un equilibrio entre el esencialismo de la Tradición clásica y el relativismo de la Recepción: el concepto de "inmanencia textual" puede ser, en este sentido, de gran productividad. De esta forma, entre el manido concepto de "fuente", del que tanto gusta hacer uso la Tradición clásica, y el de la 
"materia", tan propio de la Recepción, el intertexto supone un buen punto intermedio que concilia el doble proceso de la Tradición y la Recepción.

\section{BIBLIOGRAFÍA}

Alarcos Martínez, M., Virgilio y su reelaboración cervantina en el Persiles. Hacia una aproximación inmanente, Vigo, Academia del Hispanismo, 2014.

Alberti, R., Sobre los ángeles. Yo era un tonto y lo que he visto me ha hecho dos tontos, Madrid, Cátedra, 1996.

AzAncot, N., "Entrevista a Francisco Rico", El cultural, 15 de enero, 2010. <http:// www.elcultural.es/revista/letras/Francisco-Rico/26459>.

Bergua, J., "La Tradición clásica y el concepto de influencia”, en G. Fernández Ariza (coord.), Literatura hispanoamericana del siglo XX: mímesis e iconografía, Málaga, Servicio de Publicaciones de la Universidad de Málaga, 2003.

Bloom, H., La angustia de las influencias, Caracas, Monte Ávila, 1991.

Borges, J. L., Ficciones (en Obras completas I), Buenos Aires, Emecé, 1989a.

_, La cifra (en Obras completas III), Buenos Aires, Emecé, 1989b.

-, Biblioteca Personal (en Obras completas IV), Buenos Aires, Emecé, 1996.

Budelmann, F. y J. Haubold, "Reception and Tradition", véase Hardwick \& Stray, 2011, pp. 13-28.

Calvino, I., Por qué leer los clásicos, Barcelona, Tusquets, 1993.

Comparetti, D., Virgilio nel medioevo I-II, Livorno, F. Vigo, 1872.

Croce, B., La historia como hazaña de la libertad, México, FCE, 2005.

CuRTIUs, E. R. Literatura europea y Edad Media Latina I-II, México, FCE, 1989.

ELIOT, T. S., Selected Essays, London, Faber \& Faber, 1951.

Estébanez CALDERón, D., Diccionario de términos literarios, Madrid, Alianza Editorial, 1996.

García JuRAdo, F., "En torno a los límites de la Tradición clásica: la angustia del creador y el ratón del Ars Poetica en Juan José Arreola", Praesentia. Revista venezolana de Estudios Clásicos, 1998-99, 2-3, pp. 71-85.

-, Borges, autor de la Eneida. Poética del laberinto, Madrid, Biblioteca ELR Ediciones, 2006.

—, “¿Por qué nació la juntura «Tradición Clásica»? Razones historiográficas para un concepto moderno", Cuadernos de Filología Clásica, Estudios Latinos, 27, 2007, pp. 161-192.

—, "«Todas las cosas que merecen lágrimas». Borges, traductor de Virgilio", Studi Ispanici, 35, 2010a, pp. 291-309.

-, "La ciudad invisible de los clásicos. Entre Aulo Gelio e Italo Calvino", Nova Tellus, 28, 2010b, pp. 271-300.

_, "Menéndez Pelayo y los estudios de Tradición clásica en España", Ínsula, 790, 2012a, pp. 14-17. 
-, "Aulo Gelio y la literatura española del Siglo XVI. Autor, texto, comentario y relectura moderna", Revista de literatura, 147, 2012b, pp. 31-64.

-, "Los paradigmas de La Edad Media y del Renacimiento en el estudio de la Tradición clásica”, en J. M. Baños et alii, Philologia, Universitas, Vita. Trabajos en honor de Tomás González Rolán, Madrid, Escolar y Mayo, 2014, pp. 389-397.

-, "Borges y los inicios de la seducción virgiliana. Una hermenéutica de la nostalgia”, Bulletin of Hispanic Studies, 92, 2015, pp. 991-1011.

Genette, G., Palimpsestos. La literatura en segundo grado, Madrid, Taurus, 1989.

GonzÁLEZ, M., "Sor Juana Inés de la Cruz: la educación de las mujeres y la «angustia de las influencias»", en V. Bañuls et alii (eds.), Literatura Iberoamericana y Tradición clásica, Barcelona/Valencia, Universitat Autónoma de Barcelona/ Universitat de Valencia, 1999, pp. 201-207.

Grafton, A., G. W. Most y S. Settis, Classical Tradition, Harvard, Harvard University Press, 2010.

Guillén, C., Entre lo uno y lo diverso. Introducción a la literatura comparada (Ayer y hoy), Barcelona, Tusquets, 2005 ( $1^{\mathrm{a}}$ ed. 1985).

Hardwick, L. \& C. StRay (eds.), A companion to classical receptions, Oxford, Wiley \& Sons-Blackwell, 2011.

Haro Tecglen, E., "Sobra Eurípides", El País, 28 de abril, 1987. <http://www. elpaís.com/diario/1987/04/28/cultura/546559209_850215>.

HERNÁNDEZ HeNRíQueZ, M., Nueva lectura, reinterpretación y actualización del mito de Teseo en la poesía española más reciente, tesis doctoral, Madrid, Universidad Autónoma de Madrid, 2010.

Highet, G., The Classical Tradition. Greek and Roman Influences on Western Literature, Oxford, Oxford Clarendon Press, 1949.

Iglesias SAntos, M., "La estética de la recepción y el horizonte de expectativas", en D. Villanueva (comp.), Avances en teoría de la literatura, Santiago de Compostela, Universidad de Santiago de Compostela, 1994.

JAUSS, H. R., "La historia de la literatura como provocación de la ciencia literaria", La historia de la literatura como provocación, Barcelona, 2000, pp. 137-193.

Kennedy, D. F., "The Uses of «Reception»", en Ch. Martindale y R.F. Thomas (eds.), Classics and the Uses of Reception, Oxford, Blackwell, 2006, pp. 288-293. Laguna, G., “¿De dónde procede la denominación «Tradición clásica»?”, Cuadernos de Filología Clásica, Estudios Latinos, 24, 2004, pp. 83-93.

LIDA, M M R., La Tradición clásica en España, Barcelona, Ariel, 1975.

Marías, J., Ortega. Circunstancia y vocación II, Madrid, Revista de Occidente, 1973.

Menéndez Pelayo, M., Historia de los heterodoxos españoles II, Madrid, Consejo Superior de Investigaciones Científicas, 1946-1948.

Molina, C. A., Lugares donde se calma el dolor, Barcelona, Ediciones Destino, 2009.

Ortega, J., Meditaciones del Quijote, Madrid, Universidad Complutense, 2005. Paz, O., Los hijos del limo, Barcelona, Seix Barral, 1993. 
